\title{
A PROSPECTIVE STUDY OF ANTIBIOGRAM OF VANCOMYCIN RESISTANT (VANA) GENE POSITIVE METHICILLIN SENSITIVE STAPHYLOCOCCUS AUREUS ISOLATES IN RURAL AND URBAN TERTIARY CARE SETUPS
}

\author{
Anil Kumar Hanumanthu¹, B. Srinivas ${ }^{2}$ \\ ${ }^{1}$ Assistant Professor, Department of General Medicine, Rajiv Gandhi Institute of Medical Sciences, Srikakulam, Andhra Pradesh. \\ 2Tutor, Department of Microbiology, Rajiv Gandhi Institute of Medical Sciences, Srikakulam, Andhra Pradesh.
}

\begin{tabular}{l}
\hline ABSTRACT \\
BACKGROUND \\
Vancomycin resistant Staphylococcus aureus isolates are innately resistance to other routinely used antibiotics. The present study \\
was developed in identifying the vancomycin A (vanA) gene loci among methicillin sensitive Staphylococcus aureus (MSSA) isolates \\
collected from rural and urban tertiary care setups.
\end{tabular}

\section{MATERIALS AND METHODS}

Staphylococcus aureus was confirmed by gram staining biochemical tests. Vancomycin resistance identified by agar dilution, E-test, disc diffusion and PCR methods were followed by antibiogram.

\section{RESULTS}

In this study 16665 samples were analysed, out of which 6538 were from rural and 10127 were from urban regions. In rural regions, Methicillin Sensitive Staphylococcus aureus (MSSA) constituted 401 (6.1\%) and Methicillin Resistant Staphylococcus aureus (MRSA) 531 (8.1\%); whereas in urban MSSA constituted 524 (5.2\%) and MRSA 771 (7.6\%). By using agar dilution method, Vancomycin Sensitive Staphylococcus aureus (VSSA) isolated in rural setup was 359 (89.5\%), vancomycin intermediate resistant Staphylococcus aureus (VISA) was 35 (8.7\%) and Vancomycin Resistant Staphylococcus aureus (VRSA) was 7 (1.8\%), but in case of urban setup VSSA isolated was 451 (86.1\%), VISA 52 (9.9\%) and VRSA 21 (4.0\%). VISA and VRSA strains obtained from Agar dilution method were further confirmed by E-Test, disc diffusion and PCR methods. E-Test results for rural and urban setup were VSSA 2 (4.7\%) and 1 (1.4\%); VISA 33 (78.6\%) and 51 (69.8\%); VRSA 7 (16.7\%) and 21 (28.8\%), whereas disc diffusion results shown for VISA was 31 (73.8\%) and 66 (90.4\%), but in case of PCR VISA was 32 (76.2\%) and $46(63.0 \%)$, and VRSA 7 (16.7\%) and 21 (28.8\%). Cloxacillin (COX), Azithromycin (AZM), Gentamicin (G), Ciprofloxacin (CIP), Gatifloxacin (GAT), Tetracycline (TE), Cefoperazone (CPZ) and Piperacillin with tazobactam (PIT) were found to be highly significant $(\mathrm{P}<0.05)$ and Cefuroxime (CXM) and Linezolid (LZ) were found to be not significant $(\mathrm{P}>0.05)$ in Rural and Urban tertiary care centres.

\section{CONCLUSION}

Highest drug resistance was found in VRSA and then VISA strains of both setups. Piperacillin + tazobactam, tetracycline and linezolid were found to be useful drugs in treating VISA and VRSA infections.

\section{KEYWORDS}

VISA, VRSA, Agar Dilution, E-Test, VanA Gene, Drug Resistance.

HOW TO CITE THIS ARTICLE: Hanumanthu AK, Srinivas B. A prospective study of antibiogram of vancomycin resistant (vana) gene positive methicillin sensitive staphylococcus aureus isolates in rural and urban tertiary care setups. J. Evolution Med. Dent. Sci. 2017;6(95):6959-6964, DOI: 10.14260/jemds/2017/1511

\section{BACKGROUND}

Staphylococcus aureus (SA) is responsible for a sizable number of infections globally[1]; in 1960's methicillin was the drug of choice; soon after discovery it got resistance in 1961, then alternative effective anti-Staphylococcal antibiotics such as vancomycin were introduced.[2] This is the drug of choice for the infections caused by methicillin resistant Staphylococcus aureus (MRSA) and often used empirically for the patients in critical care settings with infections like severe sepsis, pneumonias and those under umbilical catheterisation

'Financial or Other Competing Interest': None.

Submission 07-11-2017, Peer Review 05-12-2017,

Acceptance 11-12-2017, Published 23-12-2017.

Corresponding Author:

Dr. Anil Kumar Hanumanthu,

Assistant Professor

Department of General Medicine,

Rajiv Gandhi Institute of Medical Sciences (RIMS),

Srikakulam-532001, Andhra Pradesh, India.

E-mail: vasmedmicro@yahoo.com

DOI: $10.14260 /$ jemds/2017/1511

etc. in India. However, the first report of vancomycin resistance Staphylococcus aureus (VRSA) was by Hiramatsu et al (1997a, 1997b) from Japan in 1997.[3,4] Since then, there are many reports of reduced susceptibility to vancomycin from all over the world including India.[5,6,7]

There is a necessity of surveillance for $\mathrm{S}$. aureus with reduced vancomycin susceptibility (SA-RVS); however, there are roadblocks since most Microbiology Laboratories perform disc diffusion test for antibiotic susceptibility which is not reliable for vancomycin testing.[7] A survey by Centres for Diseases Control and Prevention (CDC) published in 2000, indicated that many laboratories participating in Emerging Infections Program were not using methods that can detect SA-RVS.[8] Clinical and Laboratory Standards Institute (CLSI) and European Committee on Antimicrobial Susceptibility Testing (EUCAST) guidelines for diagnosis of vancomycin susceptible S. aureus (VSSA), vancomycin intermediate S. aureus (VISA) and vancomycin resistant S. aureus (VRSA) are based on minimum inhibitory concentration (MIC) by microdilution or agar dilution methods and molecular methods. ${ }^{[6,8,9]}$ Reduced sensitivity to vancomycin in S. aureus 
occurs due to several genetic and phenotypic alterations in wild-type bacteria including altered expression of regulatory genetic elements, thickness of cell wall, changes in the penicillin binding protein (PBP) profiles and decreased cell wall autolysis.[10]

We therefore aimed to determine the prevalence of drug resistance of VISA and VRSA among methicillin sensitive Staphylococcus aureus (MSSA) in rural and urban tertiary care setups.

\section{MATERIALS AND METHODS}

\section{Study Settings}

The prospective study was carried out during August 2013 to November 2015 for a period of 2 years 4 months and the approval was given by the Institutional Ethical Committee (IEC) at Saveetha University, Chennai, Tamilnadu. The experiment was conducted in two centres: 1) Rural setup or rural tertiary care centre, Rajiv Gandhi Institute of Medical Sciences (RIMS), Srikakulam, Andhra Pradesh; and 2) Urban setup or urban tertiary care centre, Andhra Medical College (AMC), Visakhapatnam, Andhra Pradesh.

\section{Sample Selection}

A total number of 16665 samples were analysed; 6538 $(39.2 \%)$ were from rural and 10127 (60.8\%) were from urban setups. Among these total samples, pus constituted 3106 $(47.5 \%)$ and 4961 (48.9\%) in rural and urban setups respectively. Percentage of Staphylococcus aureus isolated from pus samples was more in rural setup (14.3\%) with predominance of MSSA compared to the urban setup.

\section{Confirmation and Storage of S. aureus Isolates}

Gram's staining was performed for all the samples and the likely organisms were determined. Then the pus samples were inoculated onto Blood agar, MacConkey agar and selective media (Mannitol Salt Agar) obtained from Hi-Media Laboratories Pvt. Ltd., Mumbai and incubated at $37^{\circ} \mathrm{C}$ for 24 hours. The suspected colonies of Staphylococci were taken and Gram's staining was performed. All the Gram-positive cocci in clusters were further confirmed using a battery of standard biochemical reactions including the production of bound and free coagulase enzymes using slide and tube coagulase tests based on standard methods. A known coagulase positive strain Staphylococcus aureus ATTC-25923 was used as control. All confirmed Staphylococcus aureus strains were subsequently tested for Methicillin resistance based on recommendations of Clinical Laboratory Standard Institute (CLSI). Cefoxitin disc $(30 \mu \mathrm{g}) 15$ was obtained from Hi-Media Laboratories Pvt. Ltd. to isolate MRSA and MSSA. If the zone of inhibition was $22 \mathrm{~mm}$ or less, isolates were considered as Methicillin resistant Staphylococcus aureus (MRSA) and the zone more than $22 \mathrm{~mm}$ was considered as Methicillin sensitive Staphylococcus aureus (MSSA).

\section{Determination of Minimum Inhibitory Concentrations (MIC)}

Agar dilution and E-test: As per National Committee for Clinical Laboratory Standards (NCCLS), staphylococci with MIC of vancomycin $<4 \mu \mathrm{g} / \mu \mathrm{L}$ is susceptible, while for which the MIC is $8-16 \mu \mathrm{g} / \mu \mathrm{L}$ are intermediate and those with MIC > $32 \mu \mathrm{g} / \mu \mathrm{L}$ are resistant. Briefly, gradient plates of MuellerHinton agar (Hi-media) were prepared with vancomycin $(2$ -
$32 \mathrm{mg} / \mathrm{L}$, Sigma-Aldrich); 0.5 McFarland equivalent inoculum was prepared using 18 - $24 \mathrm{hrs}$. old culture was spotted on to gradient plates. Plates were incubated overnight at $35^{\circ} \mathrm{C}$ for 24 hrs. and assessed the visible growth. E-test (A and B) was obtained ranging from 0.016 to $256 \mu \mathrm{g}$ based on the clear inhibitory zone calculated MIC. Clear intermediate resistant and resistant isolates were inoculated into the semi-solid nutrient agar and stored at $-20^{\circ} \mathrm{C}$ until further study.

\section{Genomic DNA Preparation}

Frozen Staphylococcus aureus isolates were thawed and subcultured into brain-heart infusion broth (Hi-Media, Mumbai) and incubate at $37^{\circ} \mathrm{C}$ overnight. Genomic DNA was extracted using Macherey-Nagel Nucleospin food kit. GDNA concentration was measured using Thermo Scientific NanoDrop 8000. The average concentration for every sample was about 90 - $100 \mathrm{ng} / \mu \mathrm{L}$.

\section{Conventional PCR}

A Conventional PCR was performed following modified PCR analysis by Murugkar et al (2003) ${ }^{[11]}$ to the MicroAmp® 96 Well Reaction Plate $(0.2 \mathrm{~mL})$, added $3 \mu \mathrm{L}$ buffer, $2 \mu \mathrm{L}$ dNTPs, $0.3 \mu \mathrm{L}$ Taq DNA polymerase (NEB, USA), $2 \mu \mathrm{L} 5 \mathrm{M}$ Betaine, template $2 \mu \mathrm{L}, 20$ picomoles concentration of Primer forward $2 \mu \mathrm{L}$, primer reverse $2 \mu \mathrm{L}$ and HPLC water $6.7 \mu \mathrm{L}$ and sealed accordingly with the applicator.

The \pm 1030 bp product of Vanco gene (vanA) was amplified by using primer set Forward- 5' ATGAATAGAATAAAAGTTGC 3' and Reverse- 5' TCACCCCTTTAACGCTAATA 3' (Eurofins Genomics India Pvt. Ltd.) was used. Amplification was conducted in Applied Biosystems Veriti 96 well Thermal Cycler system. The amplification by Conventional PCR process was started with an initial denaturation step $\left(94^{\circ} \mathrm{C}, 5 \mathrm{mins}\right)$ Each cycle consisted of three steps (denaturation, annealing and extension). Each PCR reaction consisted of 35 cycles of amplification (initial 10 cycles was denaturation at $94^{\circ} \mathrm{C}$ for 1 min, annealing at $57^{\circ} \mathrm{C}$ for $1 \mathrm{~min}$ and DNA chain extension at $72^{\circ} \mathrm{C}$ for $1 \mathrm{~min}$, last 25 cycles was denaturation at $94^{\circ} \mathrm{C}$ for 30 secs annealing at $62^{\circ} \mathrm{C}$ for 10 secs and DNA chain extension at $72^{\circ} \mathrm{C}$ for $30 \mathrm{secs}$ ). A final extension cycle was performed at $72^{\circ} \mathrm{C}$ for 5 mins (Applied Biosystems Veriti Thermal Cycler).

PCR products were detected by using Agarose gel electrophoresis. Electrophoresis was performed with 2\% Agarose gel (Hi-Media) prestained with $0.5 \mu \mathrm{L} / 100 \mathrm{~mL}$ of Ethidium bromide $(10 \mathrm{mg} / \mathrm{mL})$. Gels were run at $80 \mathrm{~V}$ using $1 \mathrm{X}$ TAE buffer and then photographed under UV illumination by using a Gel documentation system (UVITEC Cambridge).

Detection of susceptibility to other antimicrobial agents by disc diffusion method (Kirby-Bauer Disc diffusion method).

Antimicrobial susceptibility testing of the isolated strains of Staphylococcus aureus to various antimicrobial discs was carried out according to CLSI (2007) ${ }^{[12]}$ disc diffusion method. The S. aureus standard strain ATCC-25923 was used for quality control. All the antibiotic discs were obtained from $\mathrm{Hi}$ Media Pvt. Limited, Mumbai, India. The following antibiotics like penicillin, cloxacillin, erythromycin, azithromycin, amikacin, gentamicin, ciprofloxacin, gatifloxacin, tetracycline, cephalexin, cefuroxime, cefoperazone, linezolid and combination drug like piperacillin + tazobactam were used and the diameter of zone of inhibition was measured with the help of special scale provided by Hi-Media, Mumbai, India. 


\section{Statistical Analysis}

Data were registered in Microsoft Excel 2010 and analysed with Statistical Package for Social Science (SPSS) version 17 statistical software. Chi-square $(\mathrm{x} 2)$ test allowed us to compare the prevalence of intestinal parasites according to age and sex.

\section{RESULTS}

In this study 16665 samples were analysed, out of which 6538 were from rural and 10127 were from urban regions. In rural setup, MSSA constituted 401 (6.1\%) and MRSA constituted $531(8.1 \%)$. Whereas in urban setup, MSSA constituted 524 (5.2\%) and MRSA constituted 771 (7.6\%) (Table 1). Percentage of Staphylococcus aureus (14.3\%) isolated from pus samples was more in rural setup with a predominance of MRSA (8.1\%) when compared to urban setup. Isolation of MSSA $43 \%$ and $40.5 \%$ and MRSA $57 \%$ and $59.5 \%$ in rural and urban setups respectively were found to be not significant.

In rural setup, out of 401 MSSA the percent of isolated was VSSA 359 (89.5\%), VISA 35 (8.7\%) and VRSA 7 (1.8\%). In urban setup, out of 524 MSSA the percent of isolated was VSSA $451(86.1 \%)$, VISA 52 (9.9\%) and VRSA 21 (4.0\%). In urban setup, percentage of VISA and VRSA isolated were compared with rural setup concentrations of vancomycin by agar dilution and distribution of VSSA. VISA and VRSA from MSSA in rural and urban tertiary care setups were found to be not significant $(\mathrm{P}>0.05$ ) by chi-square test (Table 2 ).

Results have been cross checked by E-Test, Disc diffusion and PCR methods for VISA and VRSA strains obtained from Agar dilution method. E-Test were VSSA 2 (4.7\%) and 1 (1.4\%); VISA 33 (78.6\%) and 51 (69.8\%); VRSA 7 (16.7\%) and $21(28.8 \%)$. Disc diffusion were only VISA 31 (73.8\%), 66 (90.4\%) and PCR were VISA 32 (76.2\%), 46 (63.0\%) and VRSA were $7(16.7 \%)$ and $21(28.8 \%)$ in rural and urban setups respectively. But none of the isolates were VRSA from disc diffusion method. Comparison of VISA and VRSA strains by Agar dilution, E-test and PCR methods in Rural and Urban tertiary care centres were found to be not significant $(P>0.05)$ (Table 3).

In rural setup, drug resistance less than $50 \%$ is seen. In VISA for amikacin (34.29\%), tetracycline (25.71\%), linezolid $(0 \%)$ and piperacillin combined with tazobactam $(22.86 \%)$. In VRSA for tetracycline (42.86\%), linezolid $(0 \%)$ and piperacillin combined with tazobactam (42.86\%). In urban setup, drug resistance less than $50 \%$ is seen. In VISA for amikacin (34.62\%), gentamicin (48.08\%), tetracycline (34.62\%), linezolid (0\%) and piperacillin combined with tazobactam (26.92\%). In VRSA for amikacin (42.86\%) tetracycline $(38.10 \%)$, linezolid $(9.52 \%)$ and piperacillin combined with tazobactam (47.62\%). In both the setups, VISA and VRSA are sensitive to amikacin, tetracycline, linezolid and piperacillin combined with tazobactam. Antibiogram of Penicillin (P), Erythromycin (E), Amikacin (AK) and Cephalexin (CN) of VISA and VRSA were found to be significant $(\mathrm{P}<0.05)$. Cloxacillin (COX), Azithromycin (AZM), Gentamicin (G), Ciprofloxacin (CIP), Gatifloxacin (GAT), Tetracycline (TE), Cefoperazone (CPZ) and Piperacillin with Tazobactam (PIT) were found to be highly significant $(\mathrm{P}<0.05)$ and Cefuroxime (CXM) and Linezolid (LZ) were found to be not significant $(\mathrm{P}>$ 0.05) in Rural and Urban tertiary care centres (Table 4).

\section{DISCUSSION}

We have observed vancomycin resistance (vanA) gene loci in MSSA indicated that there was no relation of methicillin resistance or sensitivity of bacteria. So far there were huge published literature regarding the vancomycin intermediate or resistance among MRSA and association of SCCmec (methicillin resistant) gene, but the present study exhibited standard methods for detection of VISA and VRSA. VRSA could detect any one of the method of agar dilution, E-test and PCR. But in case of VISA standard method for detection is PCR compared to agar dilution, E-test and disc diffusion methods. In this study, we have observed 9 strains of VISA were phenotypically positive but genotypically (vanA gene loci) negative, this might be due to altered expression of regulatory genetic elements, thickness of cell wall and changes in the penicillin-binding protein (PBP) profile factors.

One control strain and the two VRSA strains from two setups were subjected to PCR amplification and Sanger sequencing. Sanger sequencing data uploaded in standard nucleotide data bank of Basic Local Alignment Search Tool (BLAST) in National Centre for Biotechnology Information (NCBI). The search portal results were compatible with vancomycin-resistant enterococci (VRE) and vancomycinresistant Staphylococci aureus (VRSA). GenBank numbers were allotted by NCBI as rural tertiary care setup MS-VRSA Banklt1890159 Seq1_SKLM3 KU641697 and urban tertiary care setup MS-VRSA Banklt1890159 Seq1_OMC3 KU641696.

Reduced sensitivity to vancomycin in S. aureus occurs due to several genetic and phenotypic alterations in wild-type bacteria including altered expression of regulatory genetic elements, thickness of cell wall, changes in the penicillinbinding protein (PBP) profiles and decreased cell wall autolysis (Hanaki et al, 1998). In the present study, isolation rate of VISA and VRSA by agar dilution in rural setup was 35 $(83.3 \%)$ and $7(16.7 \%)$, whereas in urban setup was 52 $(71.2 \%)$ and $21(28.8 \%)$ respectively. E-Test results showed VISA 33 (78.6\%) with VRSA 7 (16.7\%) and VISA 51 (69.7\%) with VRSA 21 (28.8\%) in rural and urban setups respectively. PCR results showed VISA 32 (76.2\%) with VRSA 7 (16.7\%) and VISA 46 (63.0\%) with VRSA 21 (28.8\%) in rural and urban setups respectively. By disc diffusion method VRSA was $0 \%$ in both centres, VISA 31 (73.9\%) and $66(90.4 \%)$ in rural and urban setups respectively. So we have concluded that the gold standard methods are agar dilution, PCR and E-test compared to disc diffusion method, which is not reliable. In VRSA similar results were found in the three methods. VISA strains cross checked by E-test and detected 33 and 51 after PCR amplification. VISA 32 and 46 were positive. Both the strain exhibited bands at 1032 bp position comparing with $100 \mathrm{bp}$ ladder in an agarose $2 \%$ gel.

In the present study piperacillin + tazobactam, tetracycline and linezolid were found to be useful drugs in treating VISA and VRSA infections and similar findings were observed by Rajaduraipandi $\mathrm{K}$ et al[13] with $100 \%$ sensitivity for linezolid. In the study by Rajesh Kamtikar et al,[14] highest resistance was seen with penicillin and least resistance to vancomycin and linezolid and alarming resistance to the routinely used antistaphylococcal antibiotics like erythromycin (75\% - 85\%), cephalosporins group (50\% - 100\%) and gentamicin (50\% $75 \%$ ). Rubeena Hafeez et al[15] and Maninder Kaur et al[16] recorded similar observations. In the present study resistance of Penicillin (P), Erythromycin (E), Amikacin (AK), Cephalexin $(\mathrm{CN})$, Cloxacillin (COX), Azithromycin (AZM), Gentamicin (G), 
Ciprofloxacin (CIP), Gatifloxacin (GAT), Tetracycline (TE) Cefoperazone (CPZ) and Piperacillin with tazobactam (PIT) were found to be highly significant of VISA and VRSA strains of both setups.

\begin{tabular}{|c|c|c|c|c|c|c|}
\hline $\begin{array}{c}\text { Name of Tertiary } \\
\text { Care Centre }\end{array}$ & All Samples & Pus Samples & $\begin{array}{c}\text { Staphylococcus } \\
\text { Spp. }\end{array}$ & $\begin{array}{c}\text { Staphylococcus } \\
\text { aureus }\end{array}$ & MSSA & MRSA \\
\hline $\begin{array}{c}\text { Rural - Rajiv Gandhi Institute } \\
\text { of Medical Sciences (RIMS) } \\
\text { Srikakulam, AP }\end{array}$ & $6538(100)$ & $3106(47.5)$ & $1920(29.4)$ & 932 (14.3) & 401 (6.13) & $531(8.12)$ \\
\hline $\begin{array}{c}\text { Urban - Andhra Medical College } \\
\text { (AMC) } \\
\text { Visakhapatnam, AP }\end{array}$ & $10127(100)$ & 4961 (49) & 2553 (25.2) & 1295 (12.8) & $524(5.17)$ & $771(7.61)$ \\
\hline
\end{tabular}

\begin{tabular}{|c|c|c|c|c|c|c|c|}
\hline \multirow{3}{*}{ Name of the Centre } & \multirow{3}{*}{$\begin{array}{c}\text { Total } \\
\text { Strains }\end{array}$} & \multirow{2}{*}{\multicolumn{2}{|c|}{$\begin{array}{c}\text { VSSA } \\
\leq 2 \mathrm{mcg}\end{array}$}} & \multirow{2}{*}{\multicolumn{2}{|c|}{$\begin{array}{c}\text { VISA } \\
4-8 \mathrm{mcg}\end{array}$}} & \multirow{2}{*}{\multicolumn{2}{|c|}{$\begin{array}{c}\text { VRSA } \\
\geq 16 \mathrm{mcg}\end{array}$}} \\
\hline & & & & & & & \\
\hline & & No & $\%$ & No & $\%$ & No & $\%$ \\
\hline $\begin{array}{l}\text { Rural tertiary } \\
\text { care setup }\end{array}$ & 401 & 359 & 89.5 & 35 & 8.7 & 7 & 1.7 \\
\hline $\begin{array}{l}\text { Urban tertiary } \\
\text { care setup }\end{array}$ & 524 & 451 & 86.1 & 52 & 9.9 & 21 & 4.0 \\
\hline
\end{tabular}

Chi-square $=4.50, \mathrm{Df}=2, \mathrm{P}$ value $=0.106$ Not significant .

\begin{tabular}{|c|c|c|c|c|c|c|c|c|}
\hline \multirow{2}{*}{$\begin{array}{c}\text { Rural } \\
\text { Tertiary } \\
\text { Care Setup }\end{array}$} & \multicolumn{2}{|c|}{$\begin{array}{c}\text { Agar Dilution } \\
(\mathrm{n}=401)\end{array}$} & \multicolumn{2}{|c|}{$\begin{array}{c}\text { E-Test } \\
(n=42)\end{array}$} & \multicolumn{2}{|c|}{$\begin{array}{c}\text { Disc Diffusion } \\
(n=42)\end{array}$} & \multicolumn{2}{|c|}{$\begin{array}{c}\text { PCR for vanA Gene } \\
((n=42)\end{array}$} \\
\hline & No & (\%) & No & (\%) & No & (\%) & No & (\%) \\
\hline VSSA & 359 & 89.5 & 2 & 4.7 & - & - & - & - \\
\hline VISA & 35 & 8.7 & 33 & 78.6 & 31 & 73.8 & 32 & 76.2 \\
\hline VRSA & 7 & 1.8 & 7 & 16.7 & - & - & 7 & 16.7 \\
\hline $\begin{array}{c}\text { Urban } \\
\text { Tertiary Care }\end{array}$ & \multicolumn{2}{|c|}{$\begin{array}{c}\text { Agar Dilution } \\
(n=524)\end{array}$} & $\begin{array}{c}\text { E-Test } \\
(n=73)\end{array}$ & & \multicolumn{2}{|c|}{$\begin{array}{c}\text { Disc Diffusion } \\
(n=73)\end{array}$} & \multicolumn{2}{|c|}{$\begin{array}{c}\text { PCR for vanA gene } \\
(n=73)\end{array}$} \\
\hline Setup & No & $(\%)$ & No & $(\%)$ & No & (\%) & No & (\%) \\
\hline VSSA & 451 & 86.1 & 1 & 1.4 & - & - & - & - \\
\hline VISA & 52 & 9.9 & 51 & 69.8 & 66 & 90.4 & 46 & 63 \\
\hline VRSA & 21 & 4 & 21 & 28.8 & - & - & 21 & 28.8 \\
\hline \multicolumn{3}{|c|}{$\begin{array}{c}\text { chi-square }=4.50 \\
\text { Df }=2 \\
P \text { value }=0.106\end{array}$} & \multicolumn{2}{|c|}{$\begin{array}{c}\text { chi-square }=3.06 \\
\text { Df }=2 \\
\text { P value }=0.217\end{array}$} & \multicolumn{2}{|c|}{ - } & \multicolumn{2}{|c|}{$\begin{array}{c}\text { chi-square }=2.28 \\
\text { Df }=1 \\
\mathrm{P} \text { value }=0131\end{array}$} \\
\hline
\end{tabular}

\begin{tabular}{|c|c|c|c|c|c|c|c|c|c|c|c|c|}
\hline \multirow{3}{*}{$\begin{array}{c}\text { Name of the } \\
\text { Drug }\end{array}$} & \multirow{3}{*}{$\begin{array}{c}\text { Drug } \\
\text { Content }\end{array}$} & \multirow{3}{*}{ Interpretation } & \multicolumn{5}{|c|}{ Rural Tertiary Care Setup $(n=42)$} & \multicolumn{5}{|c|}{ Urban Tertiary Care Setup ( $n=73)$} \\
\hline & & & \multicolumn{2}{|c|}{$\begin{array}{c}\text { VISA } \\
(n=35)\end{array}$} & \multicolumn{2}{|c|}{$\begin{array}{l}\text { VRSA } \\
(n=7)\end{array}$} & \multirow[t]{2}{*}{ Total } & \multicolumn{2}{|c|}{$\begin{array}{c}\text { VISA } \\
(n=52)\end{array}$} & \multicolumn{2}{|c|}{$\begin{array}{c}\text { VRSA } \\
(n=21)\end{array}$} & \multirow[t]{2}{*}{ Total } \\
\hline & & & No. & $(\%)$ & No. & $(\%)$ & & No. & $(\%)$ & No. & $(\%)$ & \\
\hline \multirow{2}{*}{ Penicillin (P) } & \multirow{2}{*}{$10 \mathrm{U}$} & $\mathrm{R}$ & 35 & 100 & 7 & 100 & 389 & 52 & 100 & 21 & 100 & 494 \\
\hline & & $\mathrm{S}$ & 0 & 0 & 0 & 0 & 12 & 0 & 0 & 0 & 0 & 30 \\
\hline \multicolumn{3}{|c|}{ Total } & 35 & 100 & 7 & 100 & 401 & 52 & 100 & 21 & 100 & 524 \\
\hline \multirow{2}{*}{ Cloxacillin (COX) } & \multirow{2}{*}{$5 \mu \mathrm{g}$} & $\mathrm{R}$ & 23 & 65.71 & 6 & 85.71 & 218 & 33 & 63.46 & 15 & 71.43 & 242 \\
\hline & & $S$ & 12 & 34.29 & 1 & 14.29 & 183 & 19 & 36.54 & 6 & 28.57 & 282 \\
\hline \multicolumn{3}{|c|}{ Total } & 35 & 100 & 7 & 100 & 401 & 52 & 100 & 21 & 100 & 524 \\
\hline \multirow{2}{*}{ Erythromycin (E) } & \multirow{2}{*}{15} & $\mathrm{R}$ & 29 & 82.86 & 7 & 100 & 320 & 42 & 80.77 & 19 & 90.48 & 386 \\
\hline & & $S$ & 6 & 17.14 & 0 & 0 & 81 & 10 & 19.23 & 2 & 9.52 & 138 \\
\hline \multicolumn{3}{|c|}{ Total } & 35 & 100 & 7 & 100 & 401 & 52 & 100 & 21 & 100 & 524 \\
\hline \multirow{2}{*}{$\begin{array}{l}\text { Azithromycin } \\
\text { (AZM) }\end{array}$} & \multirow{2}{*}{$15 \mu \mathrm{g}$} & $\mathrm{R}$ & 24 & 68.57 & 7 & 100 & 254 & 28 & 53.85 & 15 & 71.43 & 255 \\
\hline & & $\mathrm{S}$ & 11 & 31.43 & 0 & 0 & 147 & 24 & 46.15 & 6 & 28.57 & 269 \\
\hline \multicolumn{3}{|c|}{ Total } & 35 & 100 & 7 & 100 & 401 & 52 & 100 & 21 & 100 & 524 \\
\hline \multirow[b]{2}{*}{ Amikacin (AK) } & \multirow[b]{2}{*}{$30 \mu \mathrm{g}$} & $\mathrm{R}$ & 12 & 34.29 & 6 & 85.71 & 105 & 18 & 34.62 & 9 & 42.86 & 172 \\
\hline & & $S$ & 23 & 65.71 & 1 & 14.29 & 296 & 34 & 65.38 & 12 & 57.14 & 352 \\
\hline \multicolumn{3}{|c|}{ Total } & 35 & 100 & 7 & 100 & 401 & 52 & 100 & 21 & 100 & 524 \\
\hline \multirow{2}{*}{ Gentamicin (G) } & \multirow[b]{2}{*}{$10 \mu \mathrm{g}$} & $\mathrm{R}$ & 22 & 62.86 & 7 & 100 & 218 & 25 & 48.08 & 13 & 61.9 & 226 \\
\hline & & $S$ & 13 & 37.14 & 0 & 0 & 183 & 27 & 51.92 & 8 & 38.1 & 298 \\
\hline \multicolumn{3}{|c|}{ Total } & 35 & 100 & 7 & 100 & 401 & 52 & 100 & 21 & 100 & 524 \\
\hline \multirow{2}{*}{$\begin{array}{l}\text { Ciprofloxacin } \\
\text { (CIP) }\end{array}$} & \multirow{2}{*}{$5 \mu \mathrm{g}$} & $\mathrm{R}$ & 30 & 85.71 & 7 & 100 & 312 & 40 & 76.92 & 19 & 90.48 & 312 \\
\hline & & $S$ & 5 & 14.29 & 0 & 0 & 89 & 12 & 23.08 & 2 & 9.52 & 212 \\
\hline
\end{tabular}




\begin{tabular}{|c|c|c|c|c|c|c|c|c|c|c|c|c|}
\hline \multicolumn{3}{|c|}{ Total } & 35 & 100 & 7 & 100 & 401 & 52 & 100 & 21 & 100 & 524 \\
\hline \multirow{2}{*}{$\begin{array}{c}\text { Gatifloxacin } \\
\text { (GAT) }\end{array}$} & \multirow{2}{*}{$5 \mu \mathrm{g}$} & $\mathrm{R}$ & 32 & 91.43 & 7 & 100 & 334 & 38 & 73.08 & 16 & 76.19 & 371 \\
\hline & & $\mathrm{S}$ & 3 & 8.57 & 0 & 0 & 67 & 14 & 26.92 & 5 & 23.81 & 153 \\
\hline \multicolumn{3}{|c|}{ Total } & 35 & 100 & 7 & 100 & 401 & 52 & 100 & 21 & 100 & 524 \\
\hline \multirow{2}{*}{ Tetracycline (TE) } & \multirow[b]{2}{*}{$30 \mu \mathrm{g}$} & $\mathrm{R}$ & 9 & 25.71 & 3 & 42.86 & 46 & 18 & 34.62 & 8 & 38.1 & 127 \\
\hline & & $\mathrm{S}$ & 26 & 74.29 & 4 & 57.14 & 355 & 34 & 65.38 & 13 & 61.9 & 397 \\
\hline \multicolumn{3}{|c|}{ Total } & 35 & 100 & 7 & 100 & 401 & 52 & 100 & 21 & 100 & 524 \\
\hline \multirow{2}{*}{ Cephalexin (CN) } & \multirow{2}{*}{$30 \mu \mathrm{g}$} & $\mathrm{R}$ & 21 & 60 & 7 & 100 & 209 & 36 & 69.23 & 15 & 71.43 & 275 \\
\hline & & $\mathrm{S}$ & 14 & 40 & 0 & 0 & 192 & 16 & 30.77 & 6 & 28.57 & 249 \\
\hline \multicolumn{3}{|c|}{ Total } & 35 & 100 & 7 & 100 & 401 & 52 & 100 & 21 & 100 & 524 \\
\hline \multirow{2}{*}{$\begin{array}{c}\text { Cefuroxime } \\
(\mathrm{CXM})\end{array}$} & \multirow{2}{*}{$30 \mu \mathrm{g}$} & $\mathrm{R}$ & 18 & 51.43 & 4 & 57.14 & 210 & 29 & 55.77 & 16 & 76.19 & 265 \\
\hline & & $\mathrm{S}$ & 17 & 48.57 & 3 & 42.86 & 191 & 23 & 44.23 & 5 & 23.81 & 259 \\
\hline \multicolumn{3}{|c|}{ Total } & 35 & 100 & 7 & 100 & 401 & 52 & 100 & 21 & 100 & 524 \\
\hline \multirow{2}{*}{$\begin{array}{l}\text { Cefoperazone } \\
\text { (CPZ) }\end{array}$} & \multirow{2}{*}{$75 \mu \mathrm{g}$} & $\mathrm{R}$ & 32 & 91.43 & 7 & 100 & 362 & 46 & 88.46 & 21 & 100 & 434 \\
\hline & & $\mathrm{S}$ & 3 & 8.57 & 0 & 0 & 39 & 6 & 11.54 & 0 & 0 & 90 \\
\hline \multicolumn{3}{|c|}{ Total } & 35 & 100 & 7 & 100 & 401 & 52 & 100 & 21 & 100 & 524 \\
\hline \multirow{2}{*}{ Linezolid (LZ) } & \multirow{2}{*}{$30 \mu \mathrm{g}$} & $\mathrm{R}$ & 0 & 0 & 0 & 0 & 6 & 0 & 0 & 2 & 9.52 & 14 \\
\hline & & $S$ & 35 & 100 & 7 & 100 & 395 & 52 & 100 & 19 & 90.48 & 510 \\
\hline \multicolumn{3}{|c|}{ Total } & 35 & 100 & 7 & 100 & 401 & 52 & 100 & 21 & 100 & 524 \\
\hline \multirow{2}{*}{\begin{tabular}{|l|} 
Piperacillin with \\
tazobactam (PIT)
\end{tabular}} & \multirow{2}{*}{$100 / 10 \mu \mathrm{g}$} & $\mathrm{R}$ & 8 & 22.86 & 3 & 42.86 & 62 & 14 & 26.92 & 10 & 47.62 & 67 \\
\hline & & $\mathrm{S}$ & 27 & 77.14 & 4 & 57.14 & 339 & 38 & 73.08 & 11 & 52.38 & 457 \\
\hline \multicolumn{3}{|c|}{ Total } & 35 & 100 & 7 & 100 & 401 & 52 & 100 & 21 & 100 & 524 \\
\hline \multicolumn{3}{|c|}{ P value $<0.05^{*}$ significant } & & & & & & & & & & \\
\hline
\end{tabular}

\section{CONCLUSION}

VISA or VRSA can be detected using any one of the method of agar dilution, E-Test or PCR, but not using by disc diffusion method because of its disc content of $30 \mu \mathrm{g}$. PCR is the more specific, sensitive and standard method in detecting even low copy number of organism. We have found that vanA gene loci can be identified in any gram-positive bacteria and which is not related to methicillin sensitive or resistant. Highest drug resistance found in VRSA, then VISA strains of both setups. Piperacillin + tazobactam tetracycline and linezolid were found to be useful drugs in treating VISA and VRSA infections.

\section{REFERENCES}

[1] Enright MC, Robinson DA, Randle G, et al. The evolutionary history of Methicillin-Resistant Staphylococcus Aureus (MRSA). Proc Natl Acad Sci USA 2002;99(11):7687-92.

[2] Rehm SJ, Tice A. Staphylococcus aureus: methicillinsusceptible S. aureus to methicillin-resistant S. aureus and vancomycin-resistant S. aureus. Clinical Infectious Diseases 2010;51(Suppl 2):S176-S82.

[3] Hiramatsu K, Aritaka N, Hanaki H, et al. Dissemination in Japanese hospitals of strains of Staphylococcus aureus heterogeneously resistant to vancomycin. Lancet (1997b)350(9092):1670-3.

[4] Hiramatsu K, Hanaki H, Ino T, et al. Methicillin-resistant Staphylococcus aureus clinical strain with reduced vancomycin susceptibility. J Antimicrob Chemother (1997a) 40(1):135-6.

[5] Howden BP, Davies JK, Johnson PDR, et al. Reduced vancomycin susceptibility in Staphylococcus aureus, including vancomycin-intermediate and heterogeneous vancomycin- intermediate strains: resistance mechanisms, laboratory detection and clinical implications. Clin Microbiol Rev 2010;23(1):99139.
[6] Tiwari HK, Sen MR. Emergence of Vancomycin Resistant Staphylococcus Aureus (VRSA) from a tertiary care hospital from northern part of India. BMC Infect Dis 2006;6:156.

[7] Thati V, Shivannavar CT, Gaddad SM. Vancomycin resistance among methicillin resistant Staphylococcus aureus isolates from intensive care units of tertiary care hospitals in Hyderabad. Indian J Med Res 2011;134(5):704-8.

[8] CLSI. Clinical and Laboratory Standards Institute. Methods for dilution antimicrobial susceptibility tests for bacteria that grow aerobically. Approved standard. CLSI Document M7-A8. 7th edn. Wayne, PA: 2009.

[9] EUCAST 2012. Guidelines for detection of resistance mechanisms and specific resistances of clinical and/or epidemiological importance. Sweden: The European Committee on Antimicrobial Susceptibility Testing. 2012. www.eucast.org.

[10] Pillai SK, Wennersten C, Venkataraman L, et al. Development of reduced vancomycin susceptibility in methicillin-susceptible Staphylococcus aureus. Clinical Infectious Diseases 2009;49(8):1169-74.

[11] Murugkar H, Rahman H, Dutta PK. Distribution of virulence genes in Salmonella serovars isolated from man and animals. Indian Journal of Medical Research 2003;117:66-70.

[12] CLSI. Clinical and Laboratory Standards Institute. Performance standards for antimicrobial susceptibility testing, 17th informational supplement (M100-517). Wayne, Pa: 2007.

[13] Rajaduraipandi K, Mani KR, Panneerselvam K, et al. Prevalence and antimicrobial susceptibility pattern of Methicillin Resistant Staphylococcus aureus: a multicenter study. Indian J Med Microbiol 2006;24(1):34-8.

[14] Kamtikar R, Mitra N. Sensitivity pattern of methicillin resistant Staphylococcus aureus isolated from surgical site infections. JBPRAU 2014;3(6):30-4. 
[15] Hafeez R, Chughtai AS, Aslam M. Prevalence and antimicrobial susceptibility of Methicillin Resistant Staphylococcus Aureus (MRSA). International J Path 2004;2(1):10-15.
[16] Kaur M, Gupte S, Aggarwal P, et al. Prevalence and antimicrobial, susceptibility pattern of Methicillin Resistant Staphylococcus Aureus (MRSA) isolates in a tertiary care hospital in Punjab. Journal of Evolution of Medical and Dental Sciences 2013;2(41):7841-6. 